
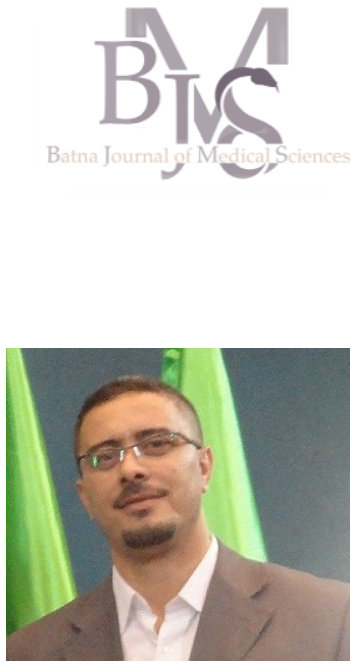

Correspondance à :

Hocine GACEM

gacem_hocine@yahoo.fr

DOI :https://doi.org/10.48087/ BJMSe.2015.2201

Il s'agit d'un article en libre accès distribué selon les termes de la licence Creative Commons Attribution International License (CC BY 4.0), qui autorise une utilisation, une distribution et une reproduction sans restriction sur tout support ou format, à condition que l'auteur original et la revue soient dûment crédités.

Pour citer l'article :

Gacem H. Batna Journal of Medical Sciences souffle sa deuxième bougie... Le défi continue. Batna J Med Sci 2015;2(2):111. https://doi.org/10.48087/ BJMSe.2015.2201

\title{
Batna Journal of Medical Sciences souffle sa deuxième bougie... Le défi continue
}

Chers lecteurs, chères lectrices,

Nous fêtons, avec ce numéro régulier de décembre 2015, le deuxième anniversaire de la revue. Je tiens, à l'occasion, à féliciter mes collègues du comité rédactionnel et éditorial et à les remercier de n'avoir ménagé aucun effort pour assurer la continuité du journal.

Voilà deux années de publication ; deux années de travail, de dévouement et de consécration, qui ont été marquées par une évolution continue. Sur le plan quantitatif, par l'augmentation globale du nombre de publications d'un numéro à l'autre, mais aussi sur le plan qualitatif par la diversité des thématiques et le nombre croissant d'articles originaux. Ce n'est qu'une partie du challenge qui est remplie; pérenniser la parution de la revue et perpétuer son évolution demeureront notre plus grand défi.

Ce progrès, aussi modeste qu'il soit, n'aurait pas été possible sans la précieuse contribution des auteurs qui ont choisi de publier à travers Batna Journal of Medical Sciences (BJMS). Nous recevons, en effet, de plus en plus de soumissions de la part d'auteurs nationaux, des différentes régions du pays, et même étrangers (Maroc et Mali). Nous sommes tout honorés d'être cet intermédiaire qui permet de faire connaitre leurs travaux scientifiques.

C'est alors avec un grand plaisir que je partage avec vous ce quatrième numéro de BJMS qui comprend une monographie dédiée à une thématique des plus intéressantes «les examens complémentaires en médecine générale », composée de sept articles avec la participation d'auteurs Algériens et Marocains sous la coordination du $\mathrm{Dr}$ Samy SLIMANI.

Comme à chaque numéro, on assiste à l'intégration d'une nouvelle forme d'articles: "l'analyse de livre » réalisée, cette foi ci, par notre collègue Dr Zoubir BENMEBAREK.
Le numéro compte également, six articles originaux ainsi qu'une série de mises au point et de cas cliniques.

Quant aux abstracts de journées et aux brèves de congrès, ils concernent la 1 ère Journée internationale de génétique de Batna 2015 et le Congrès Du Collège Américain de Rhumatologie, respectivement.

Ainsi, je vous laisse découvrir le numéro, tout en vous souhaitant une très bonne lecture et un rendez-vous dans le prochain numéro avec mon ami le $\mathrm{Dr}$ Abdelhak ABABSA MOUAKI qui prendra le relais de la rédaction -en-chef pour l'année 2016.

Dr Hocine GACEM

Rédacteur en Chef Batna Journal of Medical Sciences

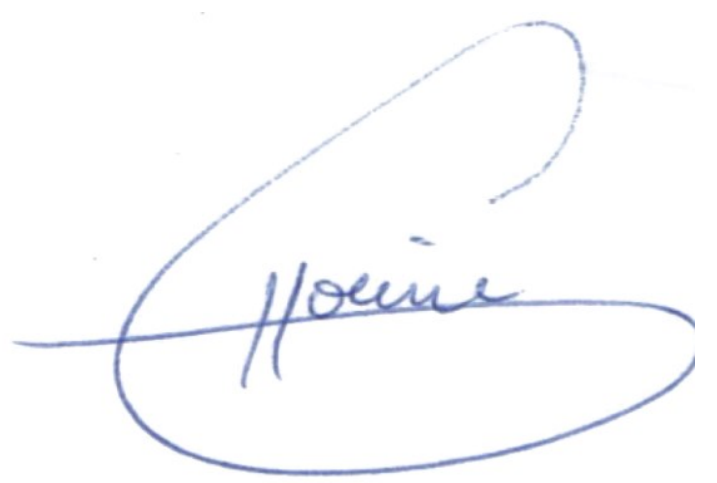

